\title{
Retained surgical sponge in differential diagnosis of paraspinal soft-tissue mass after posterior spinal surgery: Report of eight cases
}

\author{
Cem Atabey, Mehmet Turgut ${ }^{1}$, Ahmet Turan Ilica ${ }^{2}$ \\ Department of Neurosurgery, Diyarbakır Military Hospital, Diyarbakır, ${ }^{1}$ Department of Neurosurgery, Adnan Menderes University \\ School of Medicine, Aydin, ${ }^{2}$ Department of Radiology, Diyarbakır Military Hospital, Diyarbakır, Turkey
}

\section{Address for correspondence:}

Dr. M. Turgut,

Cumhuriyet Mahallesi,

Cumhuriyet Caddesi,

No: 6 Daire: 7, TR-09020 Aydın,

Turkey.

E-mail: drmturgut@yahoo.com

DOI: $10.4103 / 0028-3886.53289$

\begin{abstract}
Background: In the postoperative period of posterior spinal surgery, surgeons usually encounter a wide spectrum of complications, including retained surgical sponge, gossypiboma. Materials and Methods: Retrospective review of case records of eight patients diagnosed with gossypiboma with emphasis on computed tomography (CT) and magnetic resonance imaging (MRI) findings. Results: All the eight patients presented with low back pain and/or symptoms of infection, such as draining from the incision site, fever, and tenderness. The diagnosis was confirmed by the imaging findings on MRI with gadolinium enhancement. Conclusion: Retained paravertebral surgical sponges are seldom reported due to medicolegal implications. Awareness of this complication among neurosurgeons and radiologists is essential to avoid unnecessary morbidity.
\end{abstract}

Key words: Complication, gossypiboma, lumbar surgery, textiloma

\section{Introduction}

In medical literature, 'gossypiboma', which is derived from Latin 'gossypium' (cotton) and Kiswahili 'boma' (place of concealment), is the term used to describe a retained mass within the body. ${ }^{[1-3]}$ Other synonyms for gossypiboma are textiloma and muslinoma. Gossypiboma can trigger a granulomatous reaction after posterior spinal surgery and may result in the formation of a sizeable mass or abscess formation in the paravertebral region. ${ }^{[4,5]}$ These patients usually present with low back pain or symptoms of infection, such as fever and local tenderness with/without discharge from the incision site. ${ }^{[4]}$ However, there are few reports dealing with retained paravertebral surgical sponges in the literature. ${ }^{[1,4-16]}$

This article reports clinical and radiological findings in eight patients with gossypiboma in the paraspinal region following surgical intervention for lumbar disc herniation or spinal stenosis .

\section{Materials and Methods}

This study is a retrospective review of the medical records of eight patients with retained paravertebral surgical sponges, gossypiboma, from the neurosurgical departments, Diyarbakır Military Hospital and Adnan Menderes University Hospital, Turkey, between 2001 and 2007. All except two patients were referred from different local hospitals for further treatment. The diagnosis was established by clinical and supportive laboratory findings, including high white blood cell (WBC) counts and erythrocyte sedimentation rate (ESR), in addition to lumbar computer tomography (CT) scan and/or magnetic resonance imaging (MRI) examination. The data collected included demographic data, clinical characteristics, surgical procedure, and the 
time interval between operation and onset of symptoms [Table 1].

\section{Results}

There were six men and two woment and the mean age was 22 years (range 21-54 years). In all the eight patients the surgical procedure was lumbar laminectomy with/without discectomy for herniated disc or spinal stenosis. The time interval between the surgery and onset of symptoms ranged between 1 and 24 months [Table 1].

Low back pain at the site of lesion was the presenting feature in five and three patients with symptoms of infection such as draining from the incision site, fever and tenderness without any neurological deficit. White blood cell count ranged between $9.4 \times 10^{3}$ and $10.8 \times 10^{3} / \mathrm{mm}^{3}$ (mean, $10.2 \times 10^{3} / \mathrm{mm}^{3}$ ), and ESR first hour was between 16 and $66 \mathrm{~mm}$.

Plain radiographs of the lumbar spine showed the operation level and hemilaminectomy defect. Contrast CT scan showed a ring-enhanced hyperdense lesion with a central hypodense nidus in the paravertebral soft tissue. In Case 2, however, lumbar CT scan revealed the presence of hyperdense ovoid-shaped lesion without central hypondense nidus, consistent with hematoma, in the paravertebral region next to the laminectomy defect [Figure 1a]. In all the patients, the mass was hypointense on T1-weighted images and hyperintense on T2-weighted images [Figures $2 a-b$ and $3 a-b]$. The lesion showed ring enhancement with a hypointense necrotic center after gadolinium administration [Figures $2 c-d$ and $3 \mathrm{c}-\mathrm{d}]$.

\begin{tabular}{|c|c|c|c|c|c|c|}
\hline Age (years)/Sex (M/F) & $\begin{array}{l}\text { Surgical } \\
\text { procedure }\end{array}$ & $\begin{array}{c}\text { Interval } \\
\text { (months) }\end{array}$ & Complaints & $\begin{array}{c}\text { WBC/ } \\
\text { ESR }(\mathrm{mm} / \mathrm{hr})\end{array}$ & $\begin{array}{l}\text { Radiological } \\
\text { Modality }\end{array}$ & Outcome \\
\hline $22 / \mathrm{M}$ & Laminectomy & 6 & LBP & $10.2 / 16$ & $\mathrm{CT}, \mathrm{MRI}$ & Good \\
\hline *21/M & $\begin{array}{l}\text { Laminectomy } \\
\text { plus diskectomy }\end{array}$ & 1 & LBP & $9.4 / 22$ & $\mathrm{CT}, \mathrm{MRI}$ & Good \\
\hline $23 / M$ & $\begin{array}{l}\text { Laminectomy } \\
\text { plus diskectomy }\end{array}$ & 8 & Fever, drainage & $10.5 / 18$ & $\mathrm{CT}, \mathrm{MRI}$ & Good \\
\hline $22 / \mathrm{M}$ & $\begin{array}{l}\text { Laminectomy } \\
\text { plus diskectomy }\end{array}$ & 9 & Fever, drainage & $9.7 / 20$ & $\mathrm{CT}, \mathrm{MRI}$ & Good \\
\hline $21 / M$ & $\begin{array}{l}\text { Laminectomy } \\
\text { plus diskectomy }\end{array}$ & 24 & LBP & $10.2 / 34$ & $\mathrm{CT}, \mathrm{MRI}$ & Good \\
\hline $22 / \mathrm{M}$ & $\begin{array}{l}\text { Laminectomy } \\
\text { plus diskectomy }\end{array}$ & 2 & LBP & $10.4 / 26$ & $\mathrm{CT}, \mathrm{MRI}$ & Good \\
\hline **45/F & $\begin{array}{l}\text { Laminectomy } \\
\text { plus diskectomy }\end{array}$ & 24 & LBP, sciatica & $10.8 / 50$ & $\mathrm{CT}, \mathrm{MRI}$ & Good \\
\hline $54 / F$ & $\begin{array}{l}\text { Laminectomy } \\
\text { plus diskectomy }\end{array}$ & 9 & Swelling, drainage & $10.4 / 66$ & MRI & Good \\
\hline
\end{tabular}

CT - Computed tomography, ESR - Erytrocyte sedimentation rate, F - Female, LBP - Low back pain, M - Male, MRI - Magnetic resonance imaging, WBC - White blood cell. ${ }^{*}$ The patient was diagnosed as the hematoma formation on CT scans. ${ }^{* *}$ The case was previously reported by Turgut et al. in another journal. ${ }^{[4]}$
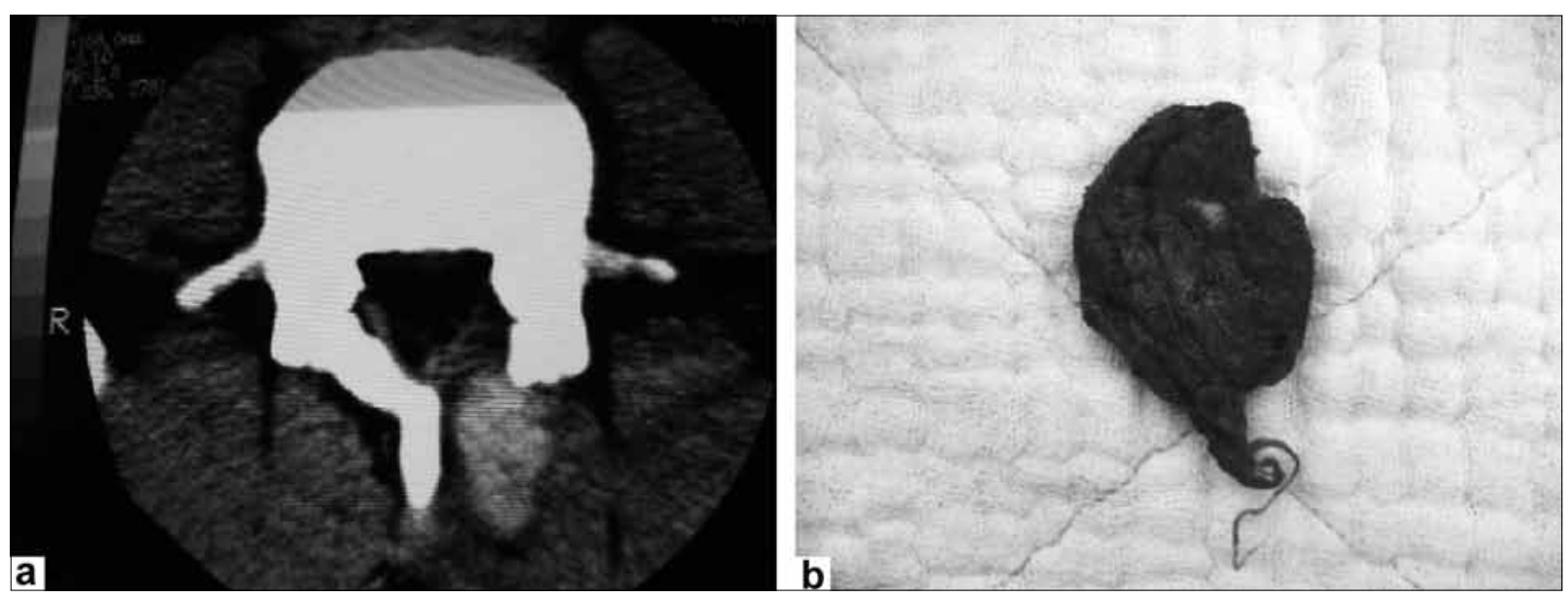

Figure 1: A 21-year-old man (Case 2) who underwent partial laminectomy and diskectomy one month before the CT examination. The CT scan (a) shows hyperdense ovoid-shaped paravertebral mass without hypondense center. Initial radiologic differential diagnosis was hematoma formation and gossypiboma. Small surgical gauze (b) forgotten during the surgical intervention was removed 

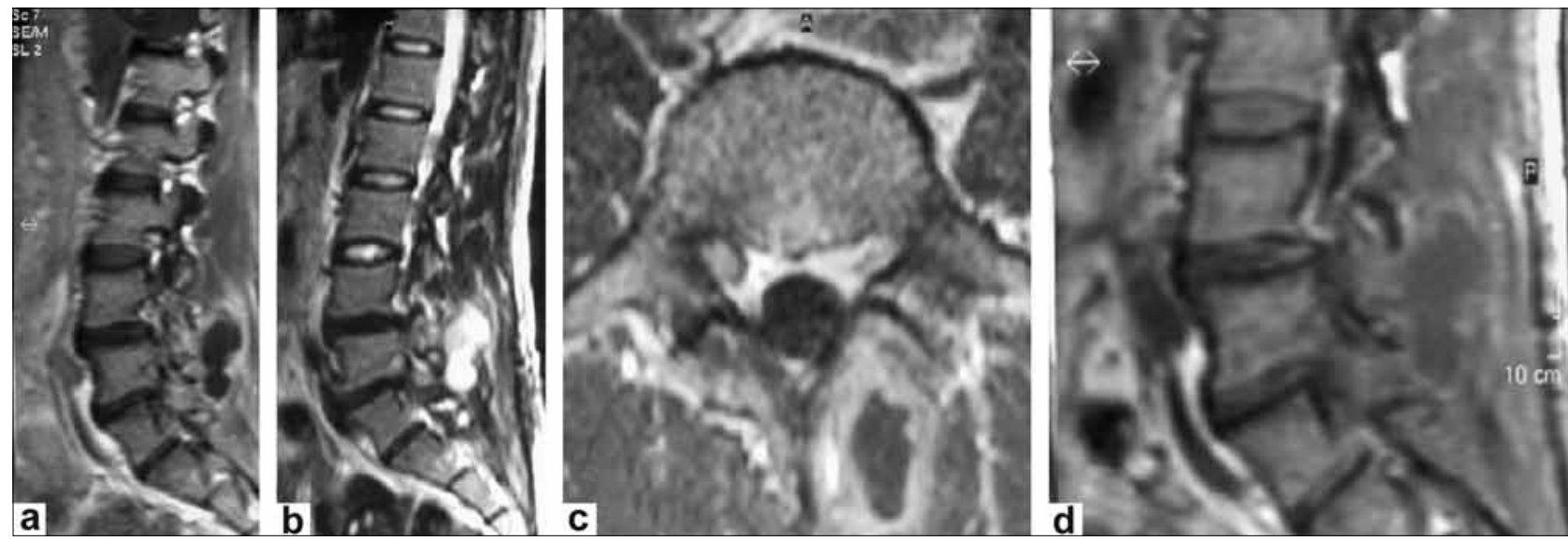

Figure 2: A 22-year-old man (Case 6) who underwent partial laminectomy and diskectomy two months before the MRI examination. The sagittal T1-weighted image (a) at the L-4 level shows the paravertebral mass with low-signal intensity. The sagittal T2-weighted image (b) shows a paravertebral mass at the L-4 level with a high-signal intensity. The axial (c) and sagittal (d) T1-weighted images with contrast enhancement show posterior paravertebral mass with peripheral rim enhancement at the same location as in a and $b$
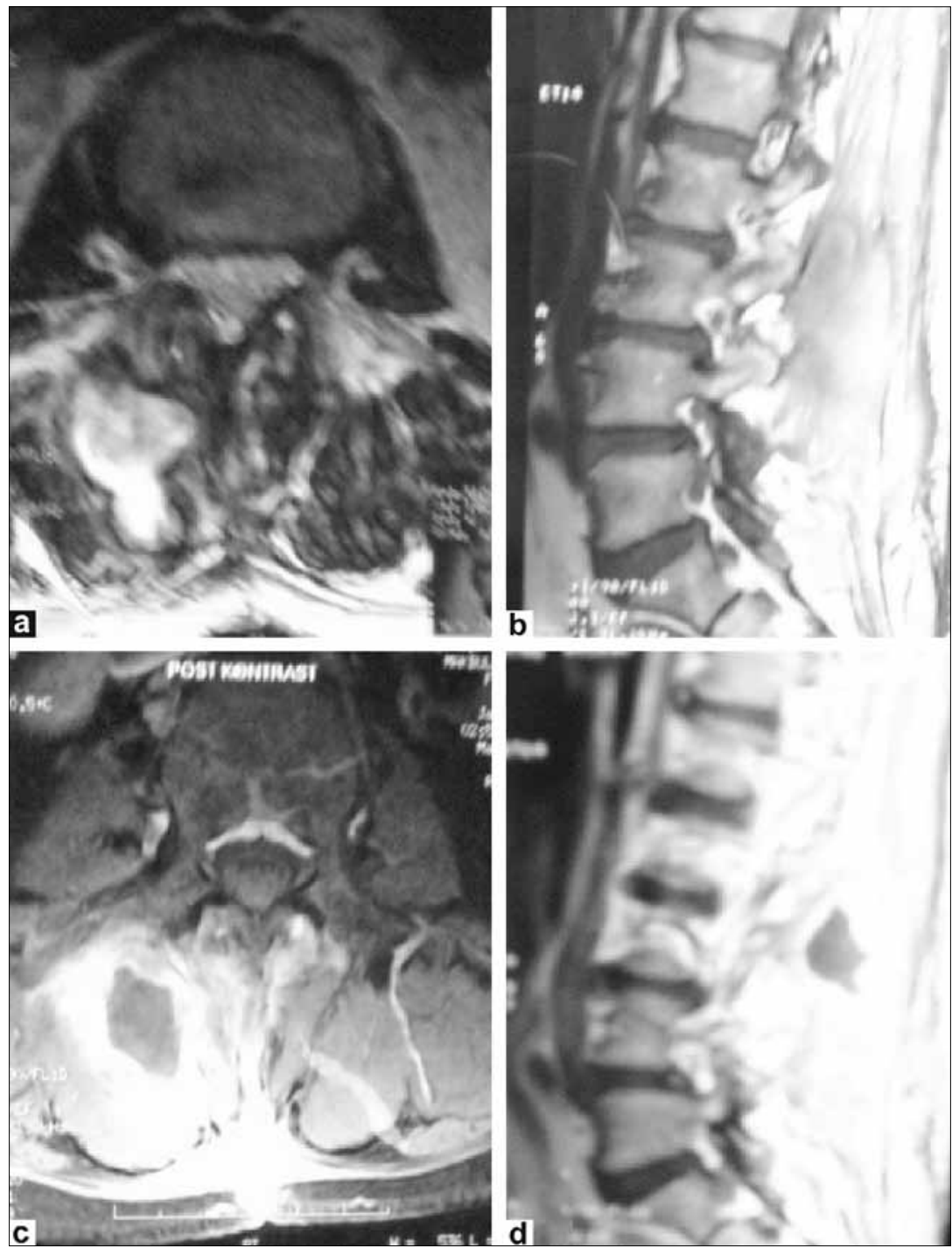

Figure 3: A 54-year-old woman (Case 8) who underwent partial laminectomy and diskectomy nine months before the MRI examination. The axial (a) and sagittal (b) T1-weighted images show the paravertebral mass with an intermediate signal intensity and multifocal high-signal-intensity spots at the L3-4 levels. The axial (c) and sagittal (d) T1-weighted images with contrast enhancement show posterior paravertebral mass with peripheral rim enhancement at the same location as in $a$ and $b$ 
In all the patients, the retained surgical sponges were removed following radiological confirmation [Figure 1b]. Of eight patients, seven received intravenous (iv) prophylactic antibiotherapy, cephazolin sodium (1 g) one hour before surgery and the same was continued for 5-7 days at a dosage of $1 \mathrm{~g} \mathrm{q} 8 \mathrm{~h}$. Patients also recieved clindamycin phosphate at a dosage of $300 \mathrm{mg}$ iv q12h. Postoperatively, the clinical symptoms resolved following the removal of the retained materials and all patients were symptom-free at discharge.

\section{Discussion}

In the postoperative period of posterior spinal surgery, surgeons encounter a wide spectrum of complications, including gossypiboma. Usually there is a delay in the diagnosis of this complication leading to delay in the institution of appropriate treatment. The reasons for the dealy in diagnosis include low index of suspicion and the long interval before the symptoms manifest.

On CT, a spongiform pattern with gas bubbles or a heterogeneous low attenuation mass with a thin highattenuation capsule are the characteristic features of retained surgical sponges..$^{[-8]}$ As exemplified in Case 2 of our series, it may lead to misdiagnosis of hematoma formation. Thus, gossypiboma should be included in the differential diagnosis of any appearance like paravertebral hematoma in postoperative period. In case of gossypiboma there is marked enhancement in postcontrast scans. ${ }^{[6-8]}$ Retained paravertebral surgical sponges appear hypointense on T1-weighted and hyperintense on T2-weighted images. ${ }^{[4]}$ Paravertebral mass may have intermediate signal intensity on T1-weighted images, possibly due to the age of the gossypiboma, as seen in Case 8. Gossypiboma exhibit strong peripheral rim enhancement on contrastenhanced T1-weighted MRI. ${ }^{[15]}$

In clinical practice, surgical sponges with radiopaque strips are routinely used as a precaution for this complication as they can easily be recognized in the postoperative radiographies and lumbar CT scans. But sponges without radiopaque strips are still being used in many centers. To overcome this problem, it is advocated that sponges must be counted during the operation and collected at the end of the operation. In cases with possible diagnosis of gossypiboma, MRI must be done and retained paravertebral surgical sponge should quickly be removed.
In conclusion, retained surgical sponges are seldom reported due to medicolegal implications. All precautions should be taken by the spinal surgeon to provide that there is no foreign body such as surgical gauze or suture material left inside the patient's body before closing of the wound. In fact, awareness of this problem among neurosurgeons and radiologists is essential to avoid unnecessary delay in the diagnosis and morbidities.

\section{References}

1. Rajput A, Loud PA, Gibbs JF, Kraybill WG. Diagnostic challenges in patients with tumors: Case 1. Gossypiboma (foreign body) manifesting 30 years after laparotomy. J Clin Oncol 2003;21:3700-1.

2. http://brighamrad.harvard.edu/Cases/bwh/hcache/391/full.html.[last accessed on 2008 Oct 30$]$.

3. http://en.wikipedia.org/wiki/Gossypiboma.[last accessed on 2008 Oct 30].

4. Turgut M, Akyüz O, Özsunar Y, Kacar F. Sponge-induced granuloma ("gauzoma") as a complication of posterior lumbar surgery - case report. Neurol Med Chir (Tokyo) 2005;45:213-5.

5. Is M, Karatas A, Akgul M, Yildirim U, Gezen F. A retained surgical sponge (gossypiboma) mimicking a paraspinal abscess. Br J Neurosurg 2007;21:307-8.

6. Yamato M, Ido K, Izutsu M, Narimatsu Y, Hiramatsu K. CT and ultrasound findings of surgically retained sponges and towels. J Comput Assist Tomogr 1987;11:1003-6.

7. Kopka L, Fischer U, Gross AJ, Funke M, Oestmann JW, Grabbe E. $\mathrm{CT}$ of retained surgical sponges (textilomas): pitfalls in detection and evaluation. J Comput Assist Tomogr 1996;20:919-23.

8. Aydogan M, Mirzanli C, Ganiyusufoglu K, Tezer M, Ozturk I. A 13-year-old textiloma (gossypiboma) after discectomy for lumbar disc herniation: A case report and review of the literature. Spine J 2007;7:618-21.

9. Van Goethem JWM, Parizel PM, Perdieus D, Hermans P, de Moor J. MR and CT imaging of paraspinal textiloma (gossypiboma). J Comput Assist Tomogr 1991;15:1000-3.

10. Kim HS, Chung TS, Suh SH, Kim SY. MR imaging findings of paravertebral gossypiboma. AJNR Am J Neuroradiol 2007;28:709-13.

11. Ford LT. Complications of lumbar-disc surgery, prevention and treatment: Local complications. J Boint Surg Am 1968;50:418-28.

12. Marquardt G, Rettig J, Lang J, Seifert V. Retained surgical sponges, a denied neurosurgical reality? Cautionary note. Neurosurg Rev 2001;24:41-3.

13. Massie JB, Heller JG, Abitbol JJ, McPherson D, Garfin SR. Postoperative posterior spinal wound infections: Avoidance of complications in spine surgery. Clin Orthop Rel Res 1992;284:99-108.

14. Ramirez LF, Thisted R. Complications and demographic characteristics of patients undergoing lumbar discectomy in community hospitals. Neurosurgery 1989;25:226-31.

15. Yamagami T, Matsui H, Tsuji H, Ichimura K, Sano A. Effects of laminectomy and retained extradural foreign body on Cauda equina adhesion. Spine 1993;18:1774-81.

16. Matsuki M, Matsuo M, Okada N. Case report: MR findings of a retained surgical sponge. Radiat Med 1998;16:65-7.

Accepted on 16-02-2009

Source of Support: Nil, Conflict of Interest: None declared. 